\title{
Bifocal distraction osteogenesis as a surgical bed for dental implants in complete maxillo-mandibular defects
}

\author{
Raúl González-García1, Luis Naval-Gías², Leticia Román-Romero³
}

${ }^{1}$ Department of Oral and Maxillofacial-Head and Neck Surgery, University Hospital Infanta Cristina, 06080 Badajoz, Spain. ${ }^{2}$ Department of Oral and Maxillofacial-Head and Neck Surgery, University Hospital La Princesa, 28047 Madrid, Spain. ${ }^{3}$ Surgical Unit, University Hospital Infanta Cristina, 06080 Badajoz, Spain.

Correspondence to: Dr. Raúl González-García, Department of Oral and Maxillofacial-Head and Neck Surgery, University Hospital Infanta Cristina, Avenida de Elvas s/n, 06080 Badajoz, Spain. E-mail: raulmaxilo@gmail.com

How to cite this article: González-García R, Naval-Gías L, Román-Romero L. Bifocal distraction osteogenesis as a surgical bed for dental implants in complete maxillo-mandibular defects. Stomatological Dis Sci 2017;1:62-8.

Dr. Raúl González-García is Oral and Maxillofacial-Head and Neck Surgeon in Spain. He works as
Consultant Surgeon at the Department of Oral and Maxillofacial Surgery, University Hospital Infanta Cristina,
Badajoz, Spain. He is actually Editor-in-Chief of Plastic and Aesthetic Research, Assistant Director of Revista
Española de Cirugía Oral y Maxilofacial, Permanent Member of the Reviewer Commitee of International
Journal of Oral and Maxillofacial Surgery in the section of TMJ Surgery, Contributing Editor of Current
Research in Dentistry, and Member of the Editorial Board/reviewer of more than 40 international journals of
the speciality. He obtained his PhD degree in Medicine and Surgery in 2011 at the Autónoma University of
Madrid School of Medicine. He is author of more than 140 publications, more than 100 of them in international
Medline/PubMed-indexed journals, 16 chapters in books of the Speciality and he is author of the text book
"Reconstrucción Maxilomandibular Compleja: Microcirugía, Distracción Ósea e Implantes dentales".

Article history:

Received: 31-12-2016

Accepted: $15-05-2017$

Published: 29-06-2017

Key words:

Bifocal distraction osteogenesis, maxillary and mandibular defects, endosseous dental implants

\begin{abstract}
Aim: To introduce bifocal distraction osteogenesis (BDO) and subsequent endosseous dental implant placement as an overall method for reconstruction of complete maxillary and mandibular segmental defects. Methods: Within the authors' whole series, 29 patients showing bony segmental defects within the maxillofacial skeleton underwent BDO. The authors focus on 3 patients who were further rehabilitated with endosseous dental implants into the distracted bone. Results: The overall BDO success rate was $79 \%$. The 3 reported cases underwent dental implant rehabilitation with 4, 6, and 5 endosseous dental implants, respectively. No relevant complications were observed, except for intraoral scarring in one patient, and pain at the end of the distraction phase in another patient. Adequate attached gingival tissue was obtained for maxillary and mandibular distracted bone in all the cases. Conclusion: Three cases of segmental maxillo-mandibular defects that have been reconstructed by bifocal distraction osteogenesis and further rehabilitated with endosseous dental implants. Surgeons must keep in mind this technique as an alternative to bone microsurgical reconstruction in cases in which free flaps are contraindicated or extended surgical time has to be avoided.
\end{abstract}

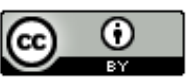

This is an open access article licensed under the terms of Creative Commons Attribution 4.0 International License (https://creativecommons.org/licenses/by/4.0/), which permits unrestricted use, distribution, and reproduction in any medium, as long as the original author is credited and the new creations are licensed under the identical terms.

For reprints contact: service@oaepublish.com

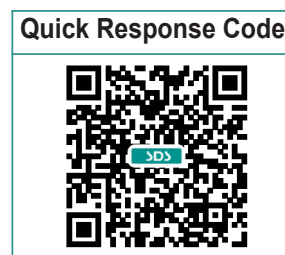




\section{INTRODUCTION}

Bifocal distraction osteogenesis (BDO) has been extensively reported for the reconstruction of deformities of the lower and upper extremities secondary to tumor ablation, trauma or congenital deformities. $^{[1-5]}$ Besides, segmental maxillomandibular defects have also been managed by means of a BDO,,$^{[6-8]}$ as it has also been proposed for closing adult bone calvarial defects. ${ }^{[9,10]}$ In addition to the restitution of normal maxillo-mandibular continuity, it has been stressed the need for a highquality alveolar soft tissue previous to the placement of endosseous dental implants. Certainly, BDO allows the reconstruction of the defect with an alveolar height which is close to that of the native mandible. It also provides an adequate attached gingiva, which is highly relevant for dental implant insertion and maintenance. ${ }^{[6]}$

BDO has been recognized as a useful technique for the treatment of patients who are not candidates for more aggressive surgery or prolonged surgical time due to poor general status, or those in whom primary treatment with osseous vascularized free flap has failed. However, little information is available concerning dental implant rehabilitation over the distracted bone and its comparison with other treatment modalities for implant rehabilitation in patients with maxillo-mandibular defects. For example, other modalities include the double-barrel free fibular flap,$^{[11]}$ free autogenous bone transplants, ${ }^{[12]}$ allografts in association with GBR procedures, ${ }^{[13]}$ xenogenic materials, ${ }^{[14]}$ or alloplastic bone substitutes. ${ }^{[15,16]}$ In a previous study by our group, ${ }^{[6]} 29$ patients showing bony segmental defects within the maxillofacial skeleton underwent BDO. Within these, more than $44 \%$ of the patients were rehabilitated with conventional endosseous dental implants up to 49 implants placed, with an overall success rate of almost $90 \%$. The quality of the attached gingiva and the absence of intraoral exposure seem to play a major role in the overall implant success rate.

In the present report, we focus on technical aspects concerning the implant rehabilitation of three patients with unique maxillo-mandibular segmental defects undergoing bone regeneration by BDO and subsequent rehabilitation with endosseous dental implants.

\section{METHODS}

\section{Patients}

Patients included in the whole series fulfilled the following inclusion criteria: (1) presence of a segmental bony defect in the upper maxilla or the mandible; (2) moderate soft-tissue defect; and (3) local or general conditions that avoid more aggressive surgery. BDO was used to reconstruct defects in all the patients. Twenty-nine patients showing bony segmental defects within the maxillofacial skeleton underwent BDO. Sixteen (55.2\%) patients were male, and $13(44.8 \%)$ were female. The mean bony defect length was $46.08 \pm 20.16 \mathrm{~mm}$ (range: $20-80$ ). The mean length of the transport disc was $13.37 \pm 7.99 \mathrm{~mm}$ (range: 4-29). The mean amount of lengthening of the distracted bone was $35.89 \pm 19.54 \mathrm{~mm}$ (range: 15-80), with an overall consolidation period of 16.36 \pm 7.79 weeks (range: $8-48$ ). Three patients, 2 men, and 1 woman were included in the present study due to special considerations regarding the distraction process and dental implant rehabilitation. In all patients, orthopantomograms were taken monthly during the distraction and consolidation phases to determine the progress of BDO.

\section{Surgical technique}

During the procedure, the lingual/palatal periosteum over the designed transport disc was maintained to preserve vascularization. If an intraoral approach is chosen, as in patient 1 for a complete maxillary defect [Figure 1], a 5-mm cuff of attached gingiva at the superior part of the alveolar process on the buccal side is preserved while making the mucoperiosteal incision. The lingual periosteum is undisturbed while a buccal mucoperiosteal flap is elevated to gain access to the osteotomy site on the buccal aspect of the mandible or maxilla. If an extraoral approach is chosen, as in patients 2 and 3 [Figures 2 and 3], the mucoperiosteal flap over the transport disc is detached at the buccal aspect of the mandible from the basilar region to an imaginary line $5 \mathrm{~mm}$ below the upper part of the alveolar process. In both intraoral and extraoral approaches, this cuff of gingiva was left attached to the transport disc to ensure adequate lengthening of the native attached gingiva. An osteotomy was performed at a variable distance from the defect to create the transport disc. A unidirectional distraction device (Modus MDO 1.5, Medartis AG, Basel, Switzerland) was placed. The moveable part of the distraction device was fixed to the transport disc by two bicortical 10 to $14 \mathrm{~mm}$ length screws. Two additional bicortical screws fixed the device to the residual bone. After verifying the mobility of the distractor, the device was returned to its original position with the distractor activator placed intra-orally or percutaneously. The latency period took place for ten days, after which distraction was initiated at a rate of $0.5 \mathrm{~mm} /$ day. The distraction phase continued 
until the transport disc reached the distal stump, while the consolidation period ranged from 16 to 20 weeks. Distraction devices used in this series allow for a maximum lengthening of $40 \mathrm{~mm}$ each one. One among 3 reported patients underwent a corticotomy in the distal stump of the transported bone and a corticotomy in the residual bone. The other 2 patients required additional bone grafting to complete bone union. Both poles were fixed with titanium mini-plates or bridging plates.
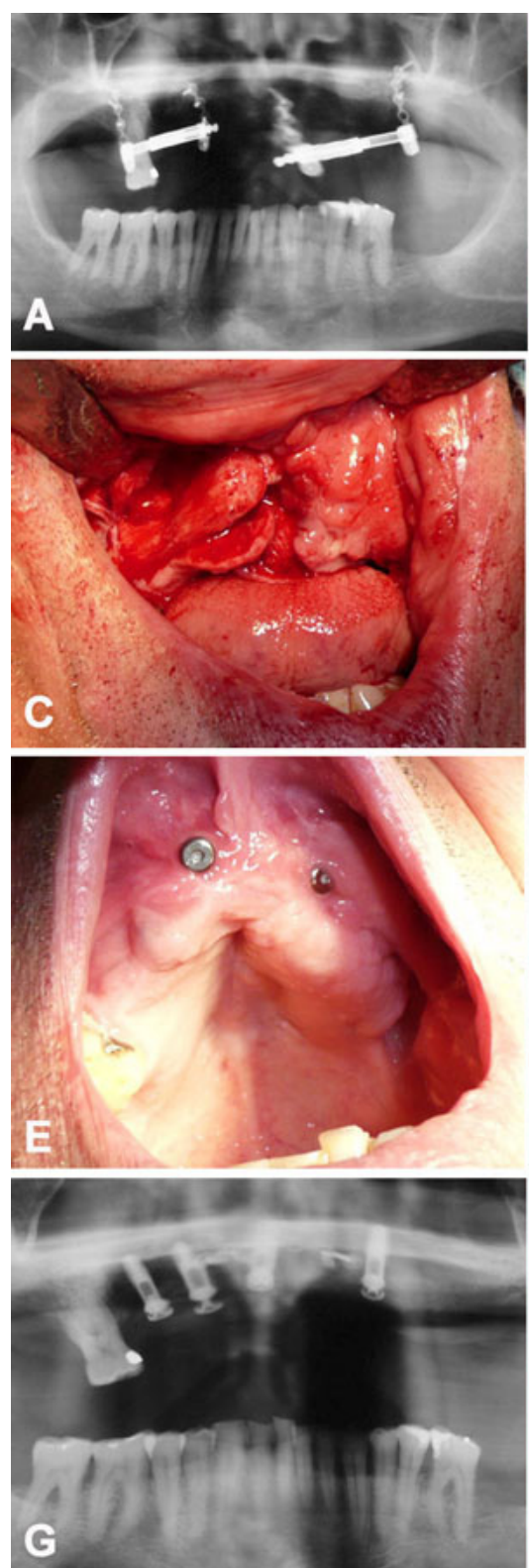

\section{RESULTS}

For the whole series of 29 patients, the overall BDO success rate was $79 \%$. At the end of the follow-up period, 49 endosseous dental implants were placed over the distracted mandible or maxilla in $13(44.8 \%)$ patients. In relation to the reported three cases, patient 1 required reconstruction of the maxilla, while patients 2 and 3 required bilateral reconstruction of the mandibular body. Patient 1 was submitted for
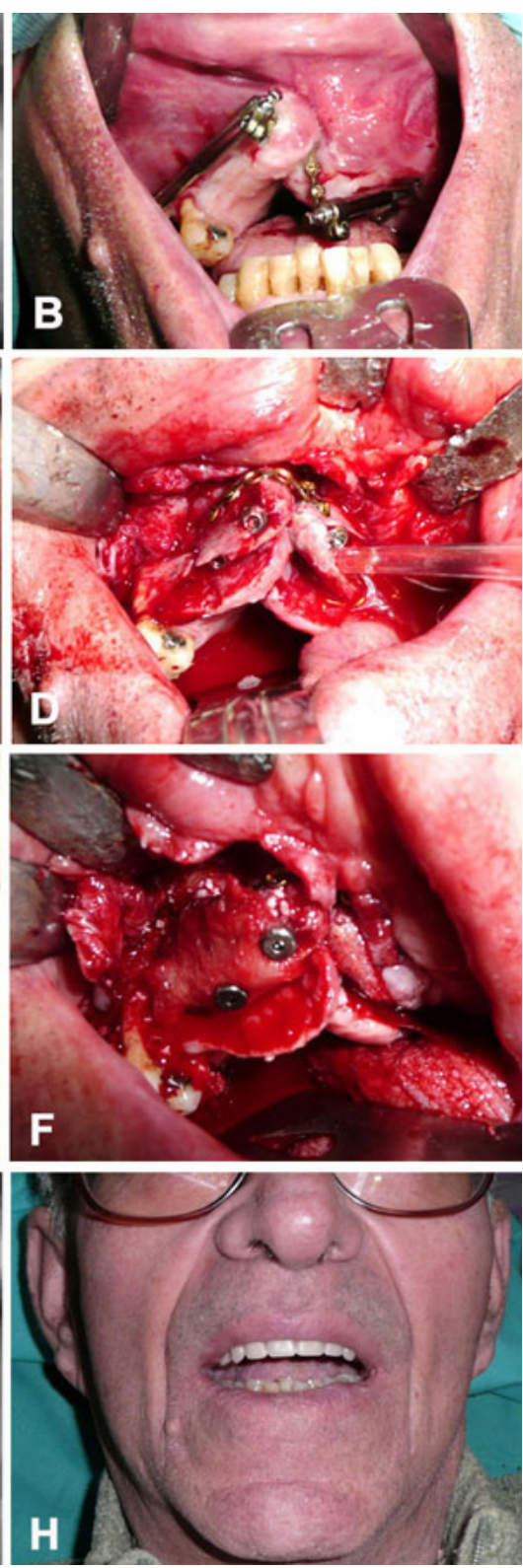

Figure 1: Patient 1. Complete anterior maxillary defect. (A) Panoramic radiography showing the placement of 2 unidirectional internal distraction osteogenesis (DO) devices, with transport disc segments designed from the posterior maxillary sites to the anterior midpoint; (B) intraoperative view during the second surgical time. Both distractors devices placed intraorally at the end of the distraction period; (C) intraoperative view, bone formation after DO; (D) endosseous dental implants placed in distracted bone segments. Note the titanium miniplate connecting both distracted poles for adequate stabilization; (E) intraoral view of the implants with adequate mucosal covering of distracted bone; $(F)$ the second surgical time of a conventional 2-stage implant procedure. Note the adequate insertion of the implants within the distracted bone; $(\mathrm{G})$ panoramic radiography showing placement of four dental implants over distracted bone; $(\mathrm{H})$ clinical view of the patient with final dental prosthetic rehabilitation 
BDO because of comorbidity that advised against microsurgical reconstruction with vascularized osseous free flaps such as the vascularized fibular free flap (VFFF). Patients 2 and 3 were submitted for BDO because of failure of previous mandibular segmental reconstruction with a VFFF. All the cases underwent successful distraction in terms of bone and soft tissue formation, although cases 2 and 3 with mandibular reconstruction underwent bone grafting with a posterior iliac crest graft to complete bone union at the symphyseal region.

The 3 reported cases underwent dental implant rehabilitation with 4,6 , and 5 endosseous dental implants, respectively. No relevant complications were observed, except for intraoral scarring in one patient, and pain at the end of the distraction phase in another patient. Adequate attached gingiva was obtained for maxillary and mandibular distracted bone in all the cases [Figures 1-3]. Patients have been followed-up for at least 10 years. No significant problems were identified during the follow-up concerning implant viability. Implants were adequately inserted at the end of the follow-up period, with no documented cases of peri-implantitis. No significant bone resorption was observed.

\section{DISCUSSION}

The BDO allows the reconstitution of the defect with an alveolar height that closely resembles the native mandible, with the advantage of a closely original attached gingiva. It is interesting to note that the attached gingiva is firmly inserted in the transport disc so that the unit bone-gingiva behaves as a unique surgical bloc during the distraction phase. Noteworthy, a careful elevation of the mucoperiosteal flap has to be performed in order to preserve the vascularization of the transport disc while maintaining the union between the attached gingiva and the underlying bone. It is the authors' experience that vascularization of the transport disc is adequately ensured by the preservation of the
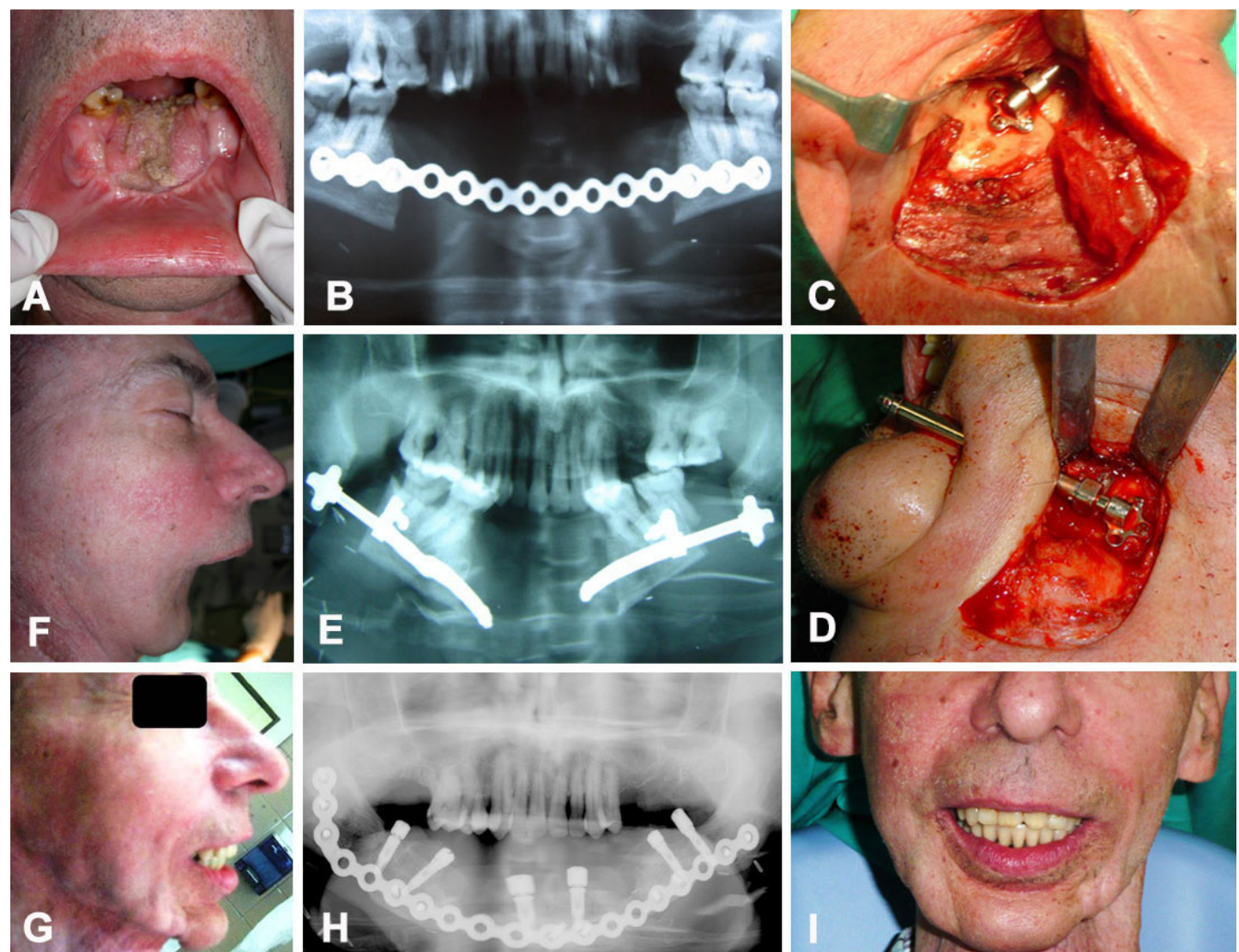

Figure 2: Patient 2. (A) Complete anterior mandibular defect; (B) preoperative orthopantomogram showing anterior segmental mandibulectomy bridged with a mandibular reconstruction plate; $(C)$ intraoperative view. The osteotomy has been performed in the left mandibular body and the distraction device has been applied in a posterior to anterior vector to distract the remaining left mandibular body; (D) identical osteotomy design and placement of the distraction osteogenesis (DO) device in the right mandibular body; (E) panoramic radiography showing distraction phase as a trifocal DO procedure. As the molar were inserted in both transport discs, they reached the anterior part of the mandible. Obviously, preservation of molars in the newly generated symphyseal region was unacceptable; (F) preoperative profile view of the patient; $(\mathrm{G})$ postoperative profile view of the patient; $(\mathrm{H})$ panoramic radiography showing placement of 6 dental implants over distracted bone and the placement of a bridging plate for stabilization purposes; (I) clinical view of the patient with final dental prosthetic restoration 

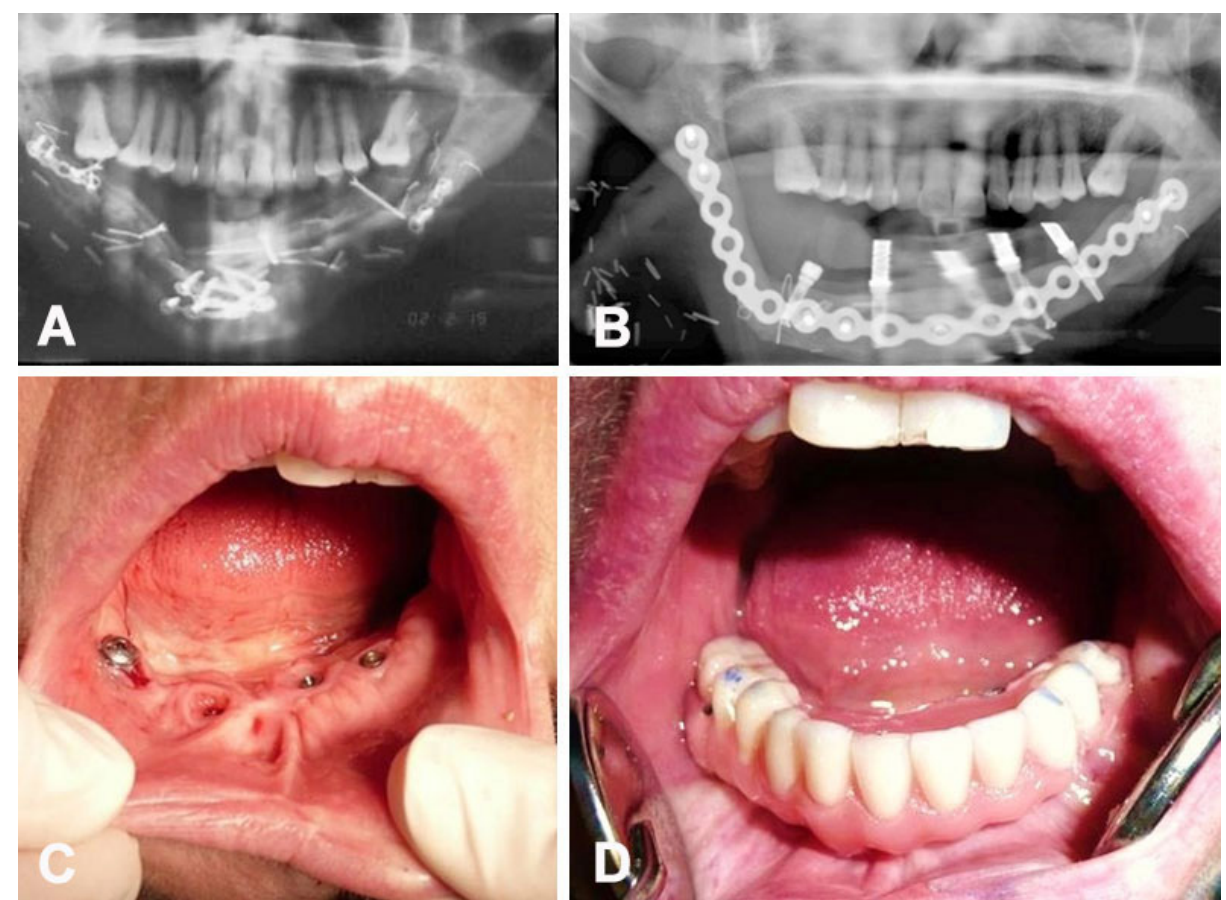

Figure 3: Patient 3. (A) Panoramic radiography showing bone segments at the end of the distraction phase. Note the presence of some titanium miniplates to provide further stabilization of the recently distracted bone; (B) panoramic radiography showing placement of a bridging plate over the complete distracted barrel and insertion of 5 endosseous dental implants over the distracted bone; (C) intraoral view of the generated gingival mucosa over the distracted bone and implant emergence profile; (D) intraoral view of the patient with final dental prosthetic restoration

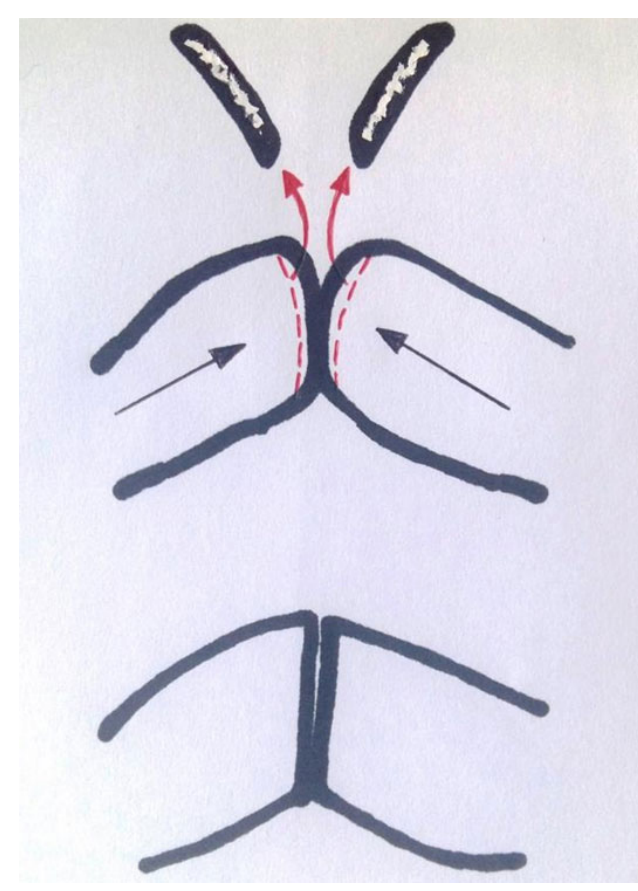

Figure 4: Diagram of corticotomy of both bone stumps to promote bone union after the distraction and consolidation phases

mucosa on the lingual aspect of the transport disc. This preservation is why the elevation of the mucoperiosteal flap over the buccal aspect of the mandible is the authors' preferred approach. This is also applies to the transport disc in the maxilla, where an elevation of the buccal mucoperiosteal flap is performed, while maintaining the palatal mucosa firmly attached. We advocate for preserving a 5-mm cuff of attached gingiva at the upper part of the alveolar process, both in edentulous or dentate patients over the transport disc. This cuff of attached gingiva on the buccal side of the mandibular-maxillary occlusal surface, together with that of the apex and the lingual/palatal gingiva provides an adequate source of attached gingival tissue for the formation of a new mucosa covering the newly generated bone.

Besides, some considerations should be highlighted regarding the bone union between the distracted bone fragment and the recipient bone. As the union of the stumps (the distracted one and the recipient one) is not always possible by simple compression after the distraction phase, some cases require either a small bone graft to interpose between the fragments by miniplate fixation; or alternatively to perform a corticotomy in both stumps to promote medullary bone contact and facilitate bone union [Figure 4]. The choice between techniques may depend on the distance between the distracted fragment and the recipient fragment. If this is irrelevant and both stumps are firmly opposed, a simple corticotomy of bone segments will be enough to promote bone union.

The methods described allow the surgeon to apply a specific solution to a given patient. In fact, the 
technique itself offers a wide variety of "tools" to be applicable for each patient. The presence of a mandibular segmental defect can be successfully reconstructed by means of the previously described "double-step transport osteogenesis", as was first described by González-García et al. ${ }^{[17]}$ Otherwise, when the defect in the mandible is limited to the alveolar region and a rigid mandibular basal bar is present, horizontal alveolar transport osteogenesis is also feasible. With this technique, appropriate height and width of bone, and simultaneous growth of the attached gingiva is provided. ${ }^{[18]}$ This is of utmost relevance to better obtain proper implant anchorage and a more esthetic prosthetic rehabilitation. Lastly, our group has developed what we called the "miniplate-guided transport osteogenesis" (MGTO). It consists of the placement of a 2.0 titanium miniplate, which is only fixated over the disc, and has a free non-screwed 4-hole segment directly opposed over the proximal bony stump. This is so the miniplate slides over the bone in a determined vector and not in aberrant vectors. This easy method has helped the authors with the control of the movement vector, avoiding the need for any other more sophisticated hardware, such as plate-guided distraction devices. ${ }^{[19]}$ MGTO may be a reliable method to avoid unnecessary hardware, such as bridging plates to guide the transport disc over the desired distraction vector.

When anticipating the placement of dental implants into mandibular or maxillary distracted bone, surgeons must keep in mind that the new generated bone may be softer than native bone in the early post-distraction osteogenesis period. This is possible despite the application of compressive forces once a week by means of a clockwise movement of the activator. This activation is in order to generate an opposing distraction vector. For the selected cases with soft bone, osteotomes are strongly recommended for implant insertion, as it has been previously suggested for the preservation of bony tissue by compressing the trabecular channels and increasing their density. ${ }^{[20]}$

In summary, three cases of segmental maxillary and mandibular defects that have been reconstructed by bifocal distraction osteogenesis and further rehabilitated with endosseous dental implants. Surgeons must keep in mind this technique as an alternative to bone microsurgical reconstruction in cases in which free flaps are contraindicated or extended surgical time has to be avoided.

\section{Authors' contributions}

Manuscript preparation: R. González-García
Manuscript's review: L. Naval-Gías

Concept design: R. González-García, L. Naval-Gías

Literature review: L. Román-Romero

\section{Acknowledgments}

We thank Dr. Jon Wagner for his contribution in language editing.

\section{Financial support and sponsorship \\ None.}

\section{Conflicts of interest}

There are no conflicts of interest.

\section{Patient consent \\ Informed consent was obtained from all the patients.}

\section{Ethics approval}

Ethics approval was obtained by the Hospital Universitario de la Princesa Ethical Review Board.

\section{REFERENCES}

1. Orzechowski W, Morasiewicz L, Dragan S, Krawczyk A, Kulej M, Mazur T. Treatment of non-union of the forearm using distractioncompression osteogenesis. Ortop Traumatol Rehabil 2007;9:357-65.

2. El-Alfy B, El-Mowafi H, Kotb S. Bifocal and trifocal bone transport for failed limb reconstruction after tumour resection. Acta Orthop Belg 2009;75:368-73.

3. Arslan H, Özkul E, Gem M, Alemdar C, Şahin İ, Kişin B. Segmental bone loss in pediatric lower extremity fractures: indications and results of bone transport. J Pediatr Orthop 2015;35:e8-12.

4. Borzunov DY, Balaev PI, Subramanyam KN. Reconstruction by bone transport after resection of benign tumors of tibia: a retrospective study of 38 patients. Indian J Orthop 2015;49:516-22.

5. Azzam W, El-Sayed M. Ilizarov distraction osteogenesis over the preexisting nail for treatment of nonunited femurs with significant shortening. Eur J Orthop Surg Traumatol 2016;26:319-28.

6. González-Garcia R, Rubio-Bueno P, Naval-Gías L, RodríguezCampo FJ, Escorial-Hernández V, Martos PL, Muñoz-Guerra MF, Sastre-Pérez J, Gil-Diez Usandizaga JL, Diaz-González FJ. Internal distraction osteogenesis inmandibular reconstruction: clinical experience in 10 cases. Plast Reconstr Surg 2008;121:563-75.

7. González-García R, Naval-Gías L. Transport osteogenesis in the maxillofacial skeleton: outcomes of a versatile reconstruction method following tumor ablation. Arch Otolaryngol Head Neck Surg 2010;136:243-50.

8. Krishnan S, Subramaniam R. Bifocal distraction to regenerate segmental mandibular defects using a custom made device: a report of two cases. Craniomaxillofac Trauma Reconstr 2010;3:97-104.

9. Seitz O, Harth M, Ghanaati S, Lehnert T, Vogl TJ, Sader R, Klein $\mathrm{CM}$. Secondary mandibular reconstruction after oral squamous cell carcinoma resection: clinical reevaluation of transport disk distraction osteogenesis. J Craniofac Surg 2010;21:59-63.

10. Bouletreau PJ, Warren SM, Paccione MF, Spector JA, McCarthy JG, Longaker MT. Transport distraction osteogenesis: a new method to heal adult calvarial defects. Plast Reconstr Surg 2002;109:1074-84.

11. Cho-Lee GY, Naval-Gías L, González-García R, Martos-Díaz PL, Muñoz-Guerra MF, Sastre-Pérez J, Rodríguez-Campo FJ. Bifocal transport osteogenesis for the reconstruction of adult calvarial defects: 
a new surgical technique. J Craniomaxillofac Surg 2010;38:368-73.

12. Bahr W, Stoll P, Wachtet R. Use of the "double barrel" free vascularized fibula in mandibular reconstruction. J Oral Maxillofac Surg 1998;56:38-44.

13. Roccuzzo M, Ramieri G, Spada M, Bianchi S, Berrone S. Vertical ridge augmentation by means of a titanium mesh and autogenous bone grafts. Clin Oral Impl Res 2004;15:73-81.

14. Simion M, Jovanovic S, Tinti C, Parma Benfenati S. Long-term evaluation of osseointegrated implant inserted at time or after vertical ridge augmentation: a retrospective study on 123 implants with 1-5 year follow-up. Clin Oral Impl Res 2001;12:35-45.

15. Artzi Z, Dayan D, Alpern Y, Nemcovsky C. Vertical ridge augmentation using xenogenic material supported by a configured titanium mesh: clinicohistopathologic and histochemical study. Int J Oral Maxillofac Impl 2003;18:440-6.

16. Block M, Kent J. Long-term radiographic evaluation of hydroxyapatite- augmented mandibular alveolar ridges. J Oral Maxillofac Surg 1984;42:793-6.

17. González-García R, Naval-Gías L, Rubio-Bueno P, RodríguezCampo FJ, Sastre-Pérez J, Muñoz-Guerra MF, Gil-Díez Usandizaga JL. Double-step transport osteogenesis in the reconstruction of mandibular segmental defects: a new surgical technique. Plast Reconstr Surg 2006;118:1608-12.

18. González-García R, Naval-Gías L. Horizontal alveolar transport osteogenesis (HATO) in case of marginal mandibular resection or inferior maxillectomy. Br J Oral Maxillofac Surg 2010;48:185-6.

19. Herford AS. Use of a plate-guided distraction device for transport distraction osteogenesis of the mandible. J Oral Maxillofac Surg 2004;62:412-20.

20. Summers RB. A new concept in maxillary implant surgery: the osteotome technique. Compendium 1994;15:152, 154-6, 158 passim, quiz 162. 